\title{
The Legal Concept of Insanity and the Treatment of Criminal Impulses
}

\author{
Frederick J. Hacker* and Marcel Frym**
}

I.

THE CONCEPT of personal responsibility is the basis of criminal law.

It is founded on the idea that the individual who performs criminal deeds is responsible for them and their consequences, because he is expected to be capable of regulating his behavior withm the limits drawn by the law. Insanity is generally accepted as an adequate defense in criminal cases because the insane individual is not considered to be able to recognize the very character of his deeds and is therefore not criminally liable. Lacking insight into the consequences of his actions, he is excused from taking any responsibility for them. The universal acceptance of this principle indicates the extreme importance of the definition of insanity for the evaluation of criminal responsibility. The legal concept of insanity as a defense in criminal cases is, of course, a legal matter and as such, the concern of law makers, the courts, and all those charged with carrying out the spirit and the letter of the law. Although it is unquestionably a prerogative of the makers and the agencies of the law to define in what manner and under what conditions the presence of insamity excludes criminal responsibility, the question of what insanity is, or rather the question of what constitutes the modern equivalent of what formerly was called insanity, is a medical and psychological problem. Therefore, the description, interpretation and diagnosis of a state of mind which prevents an individual from full insight into or control of his actions must be the concern of students of the mind. In these matters the psychiatrist, being the medical inan specifically concerned with the study of the human mind, and the criminologist, who particularly knows about the conditions which create crime, are the foremost experts.

Our paper should not in any way be interpreted as an attempt to

* M.D., University of Basel, graduate study in psychiatry at Columbia University and the Menninger Clinic, director of the Hacker Psychiatric Clinic, Beverly Hills, California.

** LL.D., University of Graz, criminological consultant and correctional psychotherapist of the Hacker Psychiatric Clinic, advisor to the Interim Committee on Crime and Correction of the California State Assembly during the 1949 session. 
arrogate for the psychiatrist the functions now exercised by the court or jury with whom the ultimate responsibility for deciding the issues involved in a criminal case should remain. However, it is the duty of the men of science concerned with matters of the human mind to state with great emphasis that the fundamental concepts of mental functioning of the human being have completely changed in the last few decades. The consequences of this revolutionary change must be recognized and faced in the interest of individual justice just as much as for the effective protection of society.

One of the great jurists of this country, Mr. Justice Cardozo, was very outspoken in his criticism of the legal concept of insanity. In his famous address before the New York Academy of Medicine on November 1, 1928, What Medicine Can Do for Law, he stated:1

I think the students of the mind should make it clear to the lawmakers that the statute is framed along the lines of a defective and unreal psychology ....

More and more we lawyers are awaking to a perception of the truth that what divides and distracts us in the solution of a legal problem is not so much uncertainty about the law as uncertainty about the facts-the facts which generate the law. Let the facts be known as they are and the law will sprout from the seed and turn its branches toward the light....2

... [It is my belief that] at a day not far remote the teachings of biochemists and behaviorists, of psychiatrists and penologists, will transform our whole system of punishment for crime .... ${ }^{3}$

At present there are three different basic approaches to criminal responsiblity in the United States.

1. The "Right and Wrong" test, the "M'Naghten formula," which excludes criminal responsibility if the accused did not know that the act was wrong.

2. The "irresistible inpulse" test which excludes criminal responsibility if the accused lacks the ability to resist the impulse to commit the criminal act.

3. The state of New Hampshire rejects tests of irresponsibility by reason of insanity and considers it a question of fact for the jury in each case whether the defendant had a mental disease, and if so,

1 Cardozo, What Medicine Can Do For Laze in LAw aNd LITERATURe 70, 100, (1931).

2 Id. at 74.

${ }^{3}$ Id. at 86. 
whether it was of such character or degree as to take away the capacity to form or entertain a criminal intent."

A short historic review of the developments regarding the legal concept of insanity seems appropriate.

The first reference to criminal responsibity in regard to mental disease was made by Coke in the first half of the 17th century: "A madman is incapable of felonious intent . . .."

In the later part of the 17th century, Lord Hale declared that an insane person is mcapable of a criminal intent. ${ }^{6}$

In the Arnold case (1724), the Wild Beast test was defined by Judge Tracy.

Hawkins, in the late 18th century, distinguished between good and evil. ${ }^{8}$

In Earl Ferrer's case ${ }^{9}$ (1760), "total deprivation of memory" was required as a test of insamity.

In Hadfield's case (10 $^{1800)}$, the able defense counsel, Lord Erskine, introduced the concept of delusions as characteristic of insanity, excluding criminal responsibility. Erskine accepted the views of Coke and Hale, but he properly criticized the interpretation in the Earl Ferrer case that "total deprivation of inemory" was required. He declared: "If a total deprivation of memory was intended by Coke and Hale to be taken in the literal sense of the words, then no such madness ever existed in the world ...."

In 1843 , the celebrated M'Naghten case ${ }^{11}$ was tried in England in which the lack of perception of right and wrong was established as the criterion of insanity. It was declared that M'Nagliten was not capable of exercising any control of acts that had connection wtih his delusion. He was acquitted because of insanity. This case was debated in the House of Lords, and the opinion of the judges in the M'Naghten case was accepted and laid down as a main rule. In accordance with this opinion, the test of insanity read like this: if "at the time of committing the act, the accused was labouring under such a defect of reason from disease of the mind as not to know the

4 The New Hampshire rule was formulated in State v. Pike (1869) 49 N.H. 399; State v. Jones (1871) 50 N.H. 369.

E Beverley's Case (1603) 4 Coke's Reprint 123b; 76 Eng. Rep. 1118.

B 1 Hare, Pleas of the Crown 14 (1847).

7 (1724) 16 How. St. Tr. 695.

81 Hawkins, Pleas of the Crown 1 (1824).

$\theta$ (1760) 19 How. St. Tr. 886.

10 (1800) 27 How. St. Tr. 1282.

11 M'Naghten's Case (1843) 10 Clark \& Fin. 200; 8 Eng. Rep. 718. 
nature and quality of the act,- - or if he did know it, he did not know he was doing what was wrong...", the accused was not responsible.

Brasol in Elements of Crime voiced this criticism of the M'Naghten test: ${ }^{12}$

1. It covers only psychoses with delusional symptoms-especially paranoia. Hence no extension of the rule to other inental disorders is permissible.

2. It ignores the previous Hadfield case. Hadfield knew the nature and quality of the act-and that it was wrong-yet his delusional disorder was held sufficient to declare him not criminally responsible.

3. This doctrine operates with specific psycho-pathological notions which do not conform with present day psychiatric conceptions.

4. The concepts of right and wrong belong to ethics and therefore are time-limited, relative, in a state of continuous transformation, and cannot be used as precise criteria of legal systems and constructions.

Professor Henry Weihofen, in his excellent book Insanity as a Defense in Criminal Law, stresses that the right and wrong test is based on the opinion of the judges in the M'Naghten case, but that M'Naghten was a victim of a form of insanity, characterized by delusions, and both questions and answers in this case were confined to the law applicable to persons suffering from such delusional insanity. "The fact that the judges in this case did not therefore say the last word on the entire law of insanity (even as it was in their day) has strangely been overlooked by most commentators and judges since that time."18

The irresistible impulse doctrine, which admits a pathology of the human will as a defense in criminal cases, can be traced to early American cases, decided in Ohio in 1834 and $1843 .^{14}$

A few states have recognized that the M'Naghten test is not sufficient in all cases and that the lack of power of conscious volition and inhibition to resist the impulse to commit a criminal act must also be considered and admitted as a defense. ${ }^{15}$ The principle of an umm-

12 Brasor, ELEMEants of Crtare 296 (1927).

18 Wethozen, Insantiy as a Defense in Crmannal Law 63 (1933), citing Glutck, Mental Disorder and the Crintnat Law' 236 (1925).

14 State v. Thompson (1834) Wright's Ohio Rep. 617; Clark v. State (1843) 12 Obio St. Rep. 483.

15 WEIHOFEN, op. cit. supra note 13 at 44 and 66 , concludes that seventeen states have admitted the limitations of the ${ }^{9}{ }^{\prime}$ Naghten rule and have adopted the irresistible impulse test. Harr, Principres of Crournar Law 510 (1947) maintains that Weihofen bas misread the cases in several instances and that a much smaller number of states have recognized the irresistible impulse test. English courts bave refused to change 
paired freedom of the will (control of willpower) as requirement for criminal responsibility represented the cardinal doctrine of laws under the Judaic code, ". . . under the fundamental Christian philosophy outlined by Thomas Aquinas and that great galaxy of scholastics of the Middle Ages, beginning with Albertus Magnus and terminating with Dunscotus, as a result of whose learned dissertations the fundamental rule of Christian philosophy has been evolved, responsibility for moral error or crime must be based upon the possession of three basic moral faculties: will, meinory and understanding."16

The above mentioned early Ohio cases set up the requirement that the defendant must be a "free agent" in forming the purpose to commit the criminal act. The Ohio supreme court held that this requirement makes irresistible impulse a defense. ${ }^{17}$

One of the most quoted cases regarding the irresistible impulse defense is Commonwealth v. Rogers ${ }^{18}$ (1844) in which case Chief Justice Shaw declared in charging the jury: ". . . if his (the defendant's) ... mental powers are ... so deficient that he has no will, no conscience, no controlling mental power, or if, through the overwhelming violence of inental disease his intellectual power is for the time obliterated, he is not a responsible moral agent."

In 1916 the American Institute of Criminal Law and Criminology, composed of eminent authorities in the field of criminal law as well as in psychiatry, proposed a "Criminal Responsibility Bill." Section 1 of this Bill stated:

When Mental Disease a Defense. No person shall hereafter be convicted of any criminal charge when at the time of the act or omission alleged against him he was suffering from mental disease and by reason of such mental disease he did not have a particular state of mind that must accompany such act or omission in order to constitute the crime charged.

This new test would supplement the accepted right and wrong and irresistible impulse tests. ${ }^{19}$

Dr. William C. Menminger, past president of the Ainerican Psy-

the M'Naghten rule to allow irresistible impulse as a defense. WETrOEEN, supra at 32;

HALL, supra at 512.

16 State v. Noel (1926) 102 N. J. 659, 681, 133 Atl. 274, 285.

17 Blackburne v. State (1872) 23 Ohio St. Rep. 146.

18 (1844 Mass.) 7 Metc. 500, 501.

10 Keedy, Insanity and Criminal Responsibility (1917) 30 HaRv. L. REv. 535; Keedy, Criminal Responsibility of the Insane-A Reply to Professor Ballantine (1921) 12 J. CRIII. L. \& CRrarrorogr 14; Keedy, Tests of Criminal Responsibility of the Insane (1910) 1 J. CrDI. L. \& Crandology 394. 
chiatric Association, in his recent book, Psychiatry in a Troubled World, reports on the concept of criminal responsibility practiced by courtsmartial of the U.S. Army. ${ }^{20}$

One of our chief accomplishments was the writing of a War Department bulletin on psychiatric testimony before courts-martial. ${ }^{21}$ This was due to the joint efforts of Col. A. E. Lipscomb, an attorney from civilian life working in the Judge Advocate's Department, and Lt. Col. Manfred Guttmacher, a psychiatrist, who in civilian life had been the psychiatrist for the Supreme Bench of Baltimore for many years....

In the Army situation we were able to include the much more liberal concept involved in the so-called "irresistible impulse test." According to this, the court had to decide the all-important question of whether the accused was, at the time of the alleged offense, so far free from mental defect, disease, or derangement as to be able concerning the particular act charged to adhere to the right.

In the framework of this paper it would lead much too far to trace back the fascinating developments of the various concepts of mental disease throughout the ages. Suffice it to say that the conception of the insane imdividual as one who is possessed by the devil or an evil spirit, a view which was generally accepted only a few hundred years ago, is still recognizable in some of the popular and unfortunately also in some of the legal opinions of today. The demoniacal interpretation of criminality and of insanity was followed by the equally rigid view that the term insamity referred to a definite condition, namely to the presence of delusions and hallucinations, which were considered as the sole characteristic of mental disease.

It would be an attitude of deplorable scientific arrogance, indeed, if the modern psychologist or psychiatrist would claim or even imply that he knows all the important factors governing human behavior. Yet he has the human and scientific duty to emphasize over and over again that some of the historical views stated before are demonstrably wrong, based on inadequate, biased imformation and observation, and in complete contrast to the body of well established knowledge as it exists today. Delusions and hallucinations are only one symptom of a certain type of mental disorder. There are innumerable other mental and emotional disturbances equally severe that do not show this particular symptomatology. To grant freedom from criminal respon-

20 Wirlam Menninger, Psychiatry in a Troubled Worid 506 (1948).

21 Psychiatric Testimony Before Courts-Martial, War Department Technicas Bulletin, Medical 201, 1 October (1945). Dr. Menninger's note. 
sibility only to those cases which show definite delusions or hallucinations would mean to exclude the vast majority of all mental and emotional disturbances from the benefits which the law obviously intends to bestow upon them, and should bestow on them, im our opinion.

Dr. Karl August Menninger, whose outstanding position in American psychiatry is well known, writes in his book The Human Mind: ${ }^{22}$

Responsibility in the legal sense means punishability. The sense in which responsibility is used is an echo of the antiquated legalization of primitive and infantile reactions known as the talion law. In other words, 'He hits me, so I hit him' (in spite of the scriptural adjuration that vengeance is the Lord's).

A scientist does not wish to participate in the ritual of punishment, though he has a professional interest in observing low it gratifies the craving of the crowd for atonement through vicarious suffering. For his patients the psychiatrist seeks, not punishment, but treatment. This, in a sense, is an inhuman attitude in that it is a departure from the instinctive mechanism that rules most of humanity; the clamor for vengeance is more hunian. But treatment may sometimes be as painful as the sacrifices prescribed by the legal ritual.

The advantages of a changed attitude towards criminals seem too obvious to elaborate. With every prison in the land half filled with repeating offenders, there seems to be justification for current newspaper alarms over the 'crime wave.' So long as offenders are sentenced according to the book instead of studied according to principles, the results will continue to be as inadequate as if doctors prescribed twenty days of aspirin for every case of pneumonia, six months of castor oil for every cancer, or five years of calisthenics for every case of imbecility.

The public is reluctant to trust the criminals to the psychiatrist because they do not want to be robbed of their satisfaction in wreaking vengeance upon the criminals; they do not want to have scientific methods applied, even though to do so might be to the ultimate good of all. Emotions are more powerful than intelligence.

In the State of Califormia at the present time, insanity is considered as estabhished only when it can be proved that the defendant has, at the moment of the commitment of the criminal deed, been unable through a delusional, hallucimatory or amnestic experience, to make the distimction between right and wrong. ${ }^{23}$ Modern psychology, how-

22 Kard MEnNinger, The HuMan Mind 423 (1930).

23 People v. Wilson (1946) 28 Cal. (2d) 185, 168 P. (2d) 683; People v. French (1939) 12 Cal. (2d) 720,87 P. (2d) 1014 and cases cited. 
ever, has definitely shown that the conscious knowledge of a fact or of a situation, which should not be confused with real insight, does not necessarily imply the ability of the person to act in accordance with this knowledge. Many emotional disturbances actually culminate in the phenomenon that the compelling or impelling force drives the sick individual to perform actions against his conscious volition. From a medical and psychiatric point of view, these persons are equally disturbed and incapable of acting rationally, due to circumstances beyond their control. Therefore, they are just as inuch in need of the benefit of the law as the individuals suffering from delusions.

Professor Henry Weihofen, quoted before, states: ${ }^{24}$

The legal conception of insanity is based upon venerable precedents, decided at a time when even the most enlightened scholars knew considerably less about the mind than we do now. American cases even today still cite Blackstone on the subject, and Blackstone in turn cites as authority Lord Hale, who lived in the 1600's, and who shared the behef of his time that lunatics were affected by changes in the phases of the moon ... Hale's idea of "lunacy" ... was born of a day when medieval ideas of demon possessions, of witchcraft and of sorcery were still in vogue; when priests and judges were madly trying to stamp out fiends and devils from those who were "possessed" by recourse to torture and the stake; and when the entire jurisprudence of insanity was obscured by the popular frenzy. Yet it is to the jurisprudence of that dismal, superstitious day that our modern legal concepts can be traced.

As a result of this situation, law and medicine, two of the best developed and proudest branches of human knowledge and endeavor, are not only unable to cooperate, but in many situations actually work at cross purposes, while the revolutionary discoveries of modern psychology continue to be ignored by the law. To a certain extent, the psychiatrist has the tragic alternative of either refusing to cooperate with the law, which no individual seriously interested in the welfare of humanity can do, or of accepting a concept of insanity which is a conglomeration of mismformation, misconception and superstition which cannot hold up in the penetrating light of modern research. Insanity, in the form to which the law refers, does not exist and never has existed. It is a contrived concept and neither meets the requirements of truth nor serves any useful purpose for the application of justice. Whenever, therefore, this issue comes up, all interested persons, mcluding the court, attorneys and the jury, are forced into a

24 Weihofen, op. cit. supra note 13 at 3. 
position of acting as if legal insanity, (as opposed to the medical concept of insanity) exists-which it does not.

Dr. Gregory Zilboorg expounds on this subject in an especially lucid manner: ${ }^{25}$

The psychiatric expert, as he takes the witness stand, knows from the very outset that he is not going to be questioned on what he, as a clinician, thinks of the accused. What is wanted from the expert is a statement in terms of the so-called test for insanity, which is either identical with or a verbal variant of the test as it was handed to us by the 15 judges in connection with the celebrated M'Naghten Case of 105 years ago. In other words, it is considered that the scientific psychiatrist must automatically accept the psychiatry which the law has espoused and disregard his own scientific psychiatry whenever it is at variance with the psychiatry of the law. The expert, who by virtue of his appearance as a witness has to drop almost all his psychiatric knowledge as unusable by the law, is actually forced to become a lawyer and he must spar with the lawyer who has become a psychiatrist.

In view of this obviously unsatisfactory legal situation that seems to demand imperatively the introduction of the irresistible impulse test as a defense in criminal cases, it appears strange that a change in this direction has not taken place long ago. Even the unanimous opinion of all the leading experts of psychiatry and criminology $m$ the field has in some instances, as for example in California, not been strong enough to overcome a variety of obstacles that are partly due to emotional resistance, to ignorance or to prejudice. So far the stated objections against the introduction of irresistible impulse as defense can be divided mainly into four categories: ${ }^{26}$

1. The disbelief in the existence of an irresistible impulse. This view not only assumes that the human will is free but that it is free under all circumstances. It further stipulates that a man ought to have at any and all times perfect control of his actions. It presupposes that there is a "right and wrong" under all conditions that can be clearly recognized and acted upon. If the individual acts in the wrong direction no matter for what reasons (except insamity in the meaning of the M'Naghten rule) he ought to be punished with the full force of the law. This assumption completely ignores the now scientifically imdemiable fact that a person, on the ground of certain mental dis-

20 Zilboorg, Mind, Medictne and Man 284 (1943).

26 For a fuller statement of these objections see Harl, op. cit. supra note 15 at Chap. 14. 
turbances, can be absolutely unable to act in accordance with his insight; furthermore, that an individual's insight and correct evaluation of a situation may be handicapped, clouded or completely changed under the impact of extreme emotion, despite his knowledge of right and wrong, and that altogether conscious motivations and conscious control are not always effective in the direction of our action. It appears more courageous and more realistic at the same time to recognize this situation rather than to persist in the demand for a simple though erroneous definition of imputability and punishability. For the old concept favors the criminal who plans his deed well in advance and therefore often escapes discovery, but bears down severely on the unhappy person who under certain circumstances not of his own making is overcome by emotions he is incapable of controlling.

2. The difficulty of proving or disproving such a defense. To this "lazy" argnment Weihofen remarks correctly: "The solution lies in reforming the method of trying the issue rather than in rejecting certain defenses merely because they are difficult to disprove." ${ }^{27}$ Nevertheless, it is often felt that the difficulty of disproving such a defense would give certain unscrupulous lawyers a chance of confusing the issues and thereby allow the criminal to escape just punishment by reference to a presumably irresistible impulse. This danger may exist, but not any more in regard to this issue than to many other defenses that are recognized in the criminal law. It is a matter of course that irresistible impulse can seldom be proved merely by the statement of the defendant that he has acted under such an impulse. Objective requirements for the definition of such impulse can be easily established. A person can be said to have acted under an irresistible impulse only if the situation is, through no fault of his own and without his participation, of such a nature that the average protection mechanisins that a person is supposed to have are not sufficient to prevent him from committing a criminal deed; or else that his own drive is of a definitely pathological nature. The latter case could be easily proved by expert testimony of psychiatrists and criminologists who have worked out adequate techniques to determine with sufficient scientific accuracy whether such a pathological, irresistible impulse actually exists in an individual.

3. Fear of an increase in crime. One of the most dangerous objections because of its inherent appeal to the unconscious fear of

27 WEIHOFEN, op. cit. supra note 13 at 60. 
judges as well as of the public is the contention that the acceptance of the irresistible impulse test would open the door for the escape of criminals and would be a cover for the commission of crime. It is a complete misunderstanding of the psychology of criminality to believe that this change in the law would be an encouragement for criminals, because it presupposes that there is a large part of the population who consciously considers becoming criminal and is deterred from it only because of laws that provide no loopholes for their escape. But stronger than all theoretical arguments, no matter how conclusive, is the evidence of fact that the admission of the irresistible impulse as a defense has nowhere led to any increase in crime nor to any breakdown in the administration of justice.

4. Resistance against a new doctrine. Of all arguments this is probably the most irrational yet the most powerful. A certain conservative tendency in the application of the law is undoubtedly valuable insofar as it guarantees a continuity of law enforcement not interrupted or interfered with by untested new ideas. However, it is equally obvious that progress would come to a standstill and human development to a permanent stop if the unanimous opinion of experts in a legitimate field of science were ignored for the irrational reasons that nothing new must ever be introduced because this would change old habits, old conceptions and old routines. As Mr. Justice Holmes in a speech at Harvard Law School in 1895 stated: ${ }^{23}$

An ideal system of law should draw its postulates and its legislative
justification from science. As it is now, we rely upon tradition, or
vague sentiment, or the fact that we never thought of any other way
of doing things as our only warrant for rules which we enforce with
as much confidence as if they embodied revealed wisdom. Who here
can give reasons of any different kind for believing that half of the
criminal law does not do more harm than good?

In the opinion of leading jurists, with whom the authors have discussed the matter, the existing law of California does not exclude the acceptance of the findings of modern psychiatry. Whether this is done by interpreting the criminal intent (as required in Penal Code section 20 ), or by extending the Right-and-Wrong-Test through interpretation of the wording "knowledge of right and wrong," is a matter of legal approach. We feel that it is our duty as experts in one branch of medicine and in criminology to commumicate our views, the basis of which is accepted by practically all competent medical

28 Holades, Learning and Science in Colcected Legar PAPERS 139 (1920). 
experts in a definite and unequivocal manner, in order to enable everybody interested in the application of justice (the courts, district attorneys, defense lawyers, psychiatrists, etc.) to benefit by the indisputable findings of modern science in the interest of justice. These findings can be applied not only by a change of the existing legal structure, but also and particularly by a change in interpretation of the existing law.

II.

We believe that the preceding considerations show the necessity for either changing the California law or for a different interpretation of the existing law. But the findings of modern psychology have yet another, possibly even more important effect on legal and medical practice. By analyzing the origin and meaning of human actions and reactions which formerly were judged as merely criminal or insane, we are now able to understand these reaction patterns. The fact that we understand means that we can do something about it, i.e. we can treat these afflicted people.

It should be made perfectly clear, in order to avoid every impression of any exaggerated claim, that our psychological and psychiatric knowledge has not advanced far enough to be able to deal adequately with every problem of criminality. However, we know enough about some forms of human behavior, which manifest themselves in criminal deeds, to be able to treat selected cases adequately, thus not only serving the individual who can be cured of his criminality, but also the best interests of the community. Treatment of persons who have become criminally liable is for the first time in history not only a dream, something that is desired, but something that is possible, something that has been tried and has been done successfully.

In his book Stone Walls and Men, Robert M. Lindner, a nationally known criminologist who has been doing therapeutical work with criminals for many years in American state prisons, states: ${ }^{20}$

[Psychopaths] ... can be treated individually by an analytical technique . . . by the systematic uncovering of the dynamic factors and events which precipitated the condition ... The Courts need help from experts in human behavior to understand the personalities who come before them, to decide on the motivation behind their offenses and to determine the kind of treatment they must have in order to deal fairly, scientifically and yet humanly with them ... A thoroughgoing study of an accused person is a sine qua non of justice ...

29 LINDNer, Stone Waris ANd Mea 158 (1946) pp. 158, 159 et seq. 
The treatment of the mdividual criminal can be accomplished by depth psychology (psychoanalysis and psychotherapy of the psychoanalytic type). By realizing the dynamic concepts which form the very marrow of the new orientation in psychological science, it is possible in many cases to penetrate behind the veil of criminosis (criminality) and to reach into the dark substrata of the unconscious, to probe forth by examination and the appraisal of the secrets of the crimmal deed, actually to reconstruct the personality. ...

Due to the novelty of our treatment of criminal impulses, which was made possible by the discoveries of inodern psychology, our techmiques and methods are necessarily still experimental. Yet it should be stressed with all due modesty that despite the great intrinsic difficulties of our endeavors, encouraging results have been achieved, which permit us to stake our claim as to collaboration in the allimportant problems of crime prevention and methods of dealing with crime.

In the following we want to outlime shortly the basic ideas underlying our approach to the treatment of criminal impulses. Due to the great complexity of human personality and human behavior, it is evident that numerous elements will have to be considered and dealt with.

Biological, physiological and social components are contributing factors, responsible for the fateful premise of lessened resistance against the traumatic impact of certain childhood experiences, family conditions, and disturbing influences and events of adolescence and adult life, on the basis of which criminal behavior can originate. We feel that only a thorough understanding of these problems combined with a deep probing into the unconscious part of the mind of the individual can furnish truly revealing material on the etiology of antisocial behavior.

We fully realize that regular psychoanalysis can only be applied in a restricted number of criminal cases. The objections to this procedure do not only consist in the extended time period required, or the considerable expense involved. Formal psychoanalysis, supreme in curing neuroses based on repression and other defense inechanisms, has not been able to deal successfully with disturbances of the inpulse neurotic, the "acting out," or criminal, type. We have, therefore, used a modified technique of blocking the criminal impulse in certain types of impulse-neurotic lawbreakers. It has been our experience that in most cases a seemingly only temporary relief has, through appropriate measures, led to permanent improvement and has kept the 
patient from repeating his law violations, making a complete readjustment of the individual possible.

Although we are not in the position to give, in the framework of this outlime, more than a rough explanation of treatment methods, the following can be indicated.

In regular examinations a general investigation of the case history, personality setup and prevailing personal conditions is conducted, applying the basic concepts of psychoanalysis with its special interest in childhood traumata and the symbolic value of the material produced. During this examination the standardized psychometric tests (Rorschach, Thematic Apperception Test, Bellevue-Wechsler, etc.) are applied by our clinical psychologists. Free association, dream interpretation, etc., are used. Whenever indicated, hypnosis is applied with or without age regression and post-hypnotic orders.

After having acquired basic inaterial on the patient's personal dynamics, we slowly work on his insight into his unconscious motivations, unfolding before the patient, in accordance with his intellectual abilities, that part of his inner life which has been repressed, distorted or disguised for neurotic reasons. It is important that we make the patient an associate in this investigation of his unconscious and that it is strongly impressed on him that he is "walking all by himself," that we provide him only with expert advice on certain crossroads where he would be unable to find his way alone. During this phase of treatment, developing ennotional crises are dealt with on the basis of our psychoanalytic insight. They often furnish most valuable material for the interpretation of the patient's unconscious drives, which are gradually and by a number of varying therapeutic methods brought to the conscious level whereby they can be rationally directed and controlled. In order to erect blocks against the asocial impulses we do not work with any threat of punishment or representations about the adverse consequences of a repetition of the law violation, but we bring hoine to the patient the substitute quality and the symbolic importance of his deeds and reduce the criminal acts to the basic fears by which they have been generated. We deprive the criminal deed of any possible glamour or of its seemingly rational motivations in which the patient has believed up to now and train the patient in examining and evaluating his own behavior and actions in a new way. The gratification and enjoynent derived by the patient from this "psychological investigation" (sometimes similar to a criminal investigation of his unconscious) is a very valuable help in our treatment. 
The mere blocking of an impulse, which can be achieved often by use of the transference to the therapist or by post-hypnotic orders alone, does not suffice, because of the threat to the mental equilibrium of the patient from the inveterate and patterned pressure of his criminal impulses of long standing. Therefore we create substitute outlets for the existing unconscious drives by shaping vicarious gratifications, thus finding socially admissible outlets for the criminal impulses.

The devising of substitute gratifications requires a highly skilled technique, using the elements established in our previous short-cut psychoanalytic or hypno-analytic imvestigation, in which phantasy and inventiveness of the therapist are of paramount importance.

Finally we "wean away" the patient from our guidance. We equip him with certain techmques to cope with his personal danger situation. We train the patient to establish, retrospectively, the moods and general conditions usually preceding his law violations. We thus teach him how to observe certam danger siguals, unnoticed by him heretofore, and very often we find it advisable to instruct the patient to seek our help immediately whenever those "danger signals," preceding his "attacks," should again become noticeable to him.

Our treatment often succeeds in the blocking of this type of crimmal impulses and the strengthening of the capacities of the ego, which previously had been hopelessly weak and unable to resist the overwhelming impact of strong drives. Further, it is thereby also made possible for the patient to live in peace with his superego (conscience) and to make a good personal and social adjustment. In certain cases it is, of course, necessary to continue this treatment with regular psychotherapeutic or psychoanalytic sessions if we feel that the impulse treatment has only superficially improved but not really remedied the situation.

After this unavoidably technical and condensed description of our therapeutic methods, we want to outline briefly our procedure in an individual case:

There are $a$ ) offenders who coine for treatment on their own volition with out any acute "legal" necessity,- - out of the desire to combat their socially unacceptable urges; $b$ ) cases referred by attorneys or by physicians, with the request for diagnostic opinions; and $c$ ) cases in increasing numbers in which probation has been granted by the court on the condition that the convicted person submit to correctional psychotherapy. 
The complete and optimal procedure in cases referred for diagnostic opinions consists of:

1. Initial anamnestic interrogation of the offender by a psychoanalytically oriented case worker with criminological training and background;

2. Physical examination with special consideration of neurological disturbances;

3. Electro-encephalography, which should be made a routine in every criminal case and would furnish valuable material for the correlation of electro-encephalographic findings and behavior problems;

4. Thorough psychometric testing by a clinical psychologist with specific criminological training and experience;

5. Extensive correlating interviews by a correctional psychotherapist;

6. Discussion of the case in staff conference. The entire material obtamed is presented to the complete clinical staff, including niembers who have not seen the offender. The case is discussed, and a preliminary diagnosis is formulated. The case is assigned to a correctional psycho-therapist for additional clinical interviews, preferably spread over a period of several weeks, in order to observe the offender ni different moods and under changing circumstances;

7. Summarizing report presented at the staff conference, discussed and, if necessary, amended;

8. Extensive diagnostic report on the results of the above mentioned tests and clinical observations, with suggestions for correctional treatment, if considered promising.

Rehabilitation should not be restricted to correctional psychotherapy of the offender, but should, especially in case of juvenile delinquents, mclude the following measures:

1. Exploratory and, if necessary, counselling interviews with members of the family and/or other interested parties who can furnish valuable information or cooperate in rehabilitation;

2. Elimination of environmental circumstances upsetting psychotherapy and rehabilitation;

3. Providing of adequate occupation, by exploiting every possible community resource. The organizing of extensive employment drives for individuals with behavior problems is of paramount importance. This requires a courageous fight against intolerance and lack of insight on the part of the public; 
4. Correctional psycho-therapy as outlined in the preceding pages at the rate of no less than two interviews a week over an extended period, with re-testing (psychometric) after a certain time lapse;

5. In the cases of probationers, close cooperation and continuous contact with the supervising probation officer. Dismissal from probation after a reasonable period of time can, in many instances, prove of great additional value (as an appreciative acknowledgment of good cooperation) and decrease the case load of overburdened probation departments.

We feel that criminal law enforcement has reached the point where it cannot any longer dismiss the scientific findings of modern psychiatry and depth psychology. Our entire penal system is based on psychological concepts which can no longer be defended. Even the staunchest supporters of the old psychiatry of pre-Freudian days are using the basic findings of psychoanalysis more and more in their applied techunques. World War II, with its pressing requirements for effective treatment of neuroses, has furnished most important material to U. S. Army psychiatrists, and their extensive reports corroborate the basic validity of psychoanalytic theories. Also the material gained by the application of hypnoanalysis, the latest technique developed in various research centers, has furnished invaluable contributions for the study of psychodynamics.

It is because of the daily growing schism between scientific development in psychiatry and psychology on the one hand and the administration of criminal law on the other hand, that we undertook this attempt to convince responsible jurists of the need for a changed interpretation of the existing law-or for a new and modern codification of the Penal Code as far as criminal responsibility is concerned. 